\title{
O semi-simbolismo como ponto de partida para o texto da telenovela
}

\author{
Elaine Aparecida Souto ANTUNES (FFLCH-USP)
}

RESUMO: A telenovela "Mulheres Apaixonadas" foi exibida pela Rede Globo de televisão, no ano de 2003. Ela se propôs a montar um painel com várias mulheres e, assim, expor seus dramas e conflitos. Neste trabalho, analisaremos o texto visual dos vinte e três segundos iniciais do primeiro capítulo dessa novela. Verificaremos, então, como se inicia essa história e, a partir disso, observaremos se existem relações semisimbólicas entre os dois planos da linguagem, o plano de conteúdo e o plano de expressão.

PALAVRAS-CHAVE: Telenovela; Semiótica; Semi- simbolismo.

ABSTRACT: "Mulheres Apaixonadas" was a soap opera air in broadcasting by Rede Globo, a Brazilian tv-station, in 2003. Its aim was to show a panel of several women and, thus, to exhibit their dramas and conflicts. From the twenty-three initial seconds from the first chapter, we will be working on the visual text analysis. We will verify how this soap opera was started and throughout this observation discuss if there is a semi- symbolic relation between the two plans of language, the contents plan and the expression plan.

KEYWORDS: soap opera; semiotics; semi- symbolism. 
“Mulheres Apaixonadas” estreou no dia 17 de fevereiro de 2003, no horário nobre da Rede Globo de televisão, às 21:00 horas.

Como o próprio nome sugere, "Mulheres Apaixonadas" se propôs a tratar do relacionamento em comum das mulheres com a vida, o amor, suas alegrias e tristezas.

Num panorama mais geral, nessa novela a protagonista Helena (Christiane Torloni) é professora, e depois de muitos anos de casamento com Téo (Toni Ramos) decide se separar e tenta reviver um romance com seu antigo namorado César (José Mayer). Após vários encontros e desencontros, no final da novela eles se casam.

Na realidade, o objetivo da novela era montar um painel de várias mulheres e suas paixões. Considerando tal objetivo da história, analisaremos neste artigo de que forma o texto de Mulheres Apaixonadas iniciou sua trajetória na televisão brasileira.

Tomaremos como corpus de análise as imagens dos vinte e três segundos iniciais da trama. Nosso propósito é analisar como o texto está construído plasticamente e, assim, verificar quais são as categorias do plano de expressão e do plano de conteúdo que foram selecionadas e articulam as relações semi-simbólicas no transcorrer das imagens. Neste exercício estamos interessados na análise plástica das imagens, portanto faremos abstração do componente sonoro.

Os vinte e três segundos iniciais da história são formados pela sequiência das sete imagens relacionadas na página seguinte. As imagens são apreendidas com a câmera parada e quem se movimenta são os vultos dos sujeitos que aparecem a partir da imagem 3. O primeiro vulto que ainda está sozinho dá pequenos saltos para criar o efeito de sentido de que está brincando na água do mar. Os outros vultos que aparecerão depois não apenas brincam, mas também apresentam um movimento de caminhada, assim criam o efeito de sentido para o enunciatário/ telespectador de que aquelas imagens retratam um amanhecer na praia.

A novela inicia-se a partir de uma imagem que se abre sobre um fundo preto, imagem 1. Conforme a imagem se amplia são construídas, na imagem 2, duas faixas azuladas com uma imagem amarela e vermelha ao meio. As faixas azuladas estão dispostas uma na parte superior da tela e outra na parte inferior. $\mathrm{Na}$ faixa superior está escrita a palavra "mulheres" e na faixa inferior a palavra "apaixonadas". Ambas as palavras estão escritas em letra de cor preta e são repetidas oito vezes tanto na parte superior quanto na parte inferior e não apresentam nenhum tipo de movimento. 


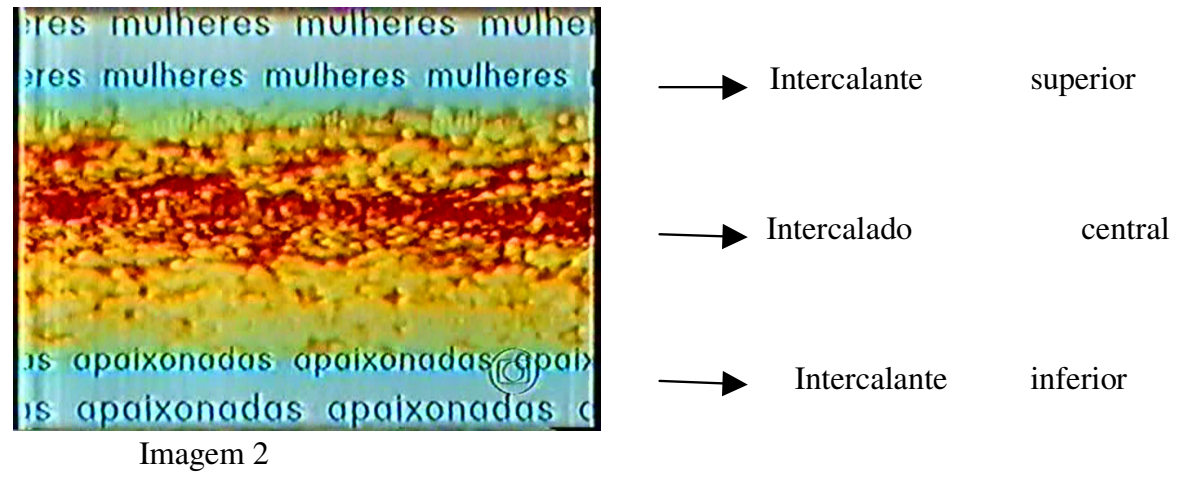

Após sete segundos de filmagem, surge a imagem 3, onde as duas faixas azuladas desapareceram e a tela é ocupada por duas faixas laranjas cortadas por uma vermelha no centro. Nessa mesma faixa vermelha está o vulto de um sujeito. Trata-se da construção de três espaços, dois intercalantes e um intercalado.

Nessa imagem as cores laranja e vermelha se misturam na faixa intercalada e nas faixas intercalantes a cor laranja predomina, sendo que ela é mais luminosa, deste modo, criando o efeito de sentido de reflexo do sol na água.

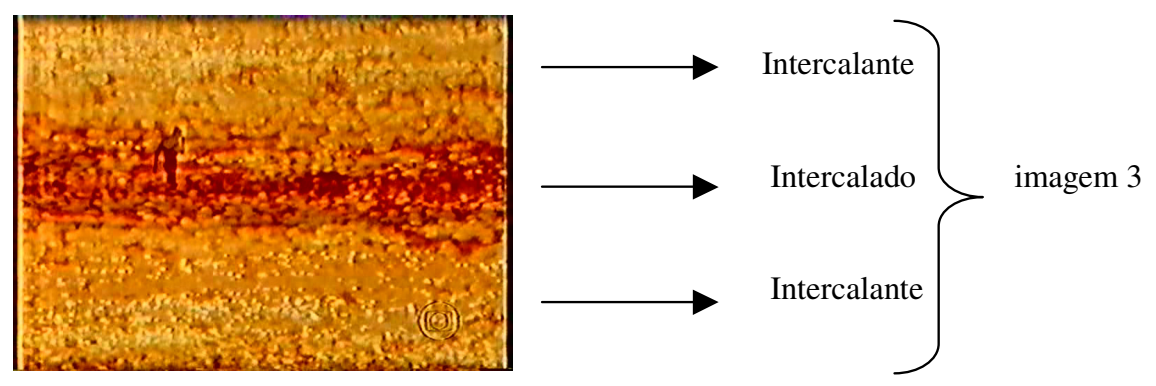

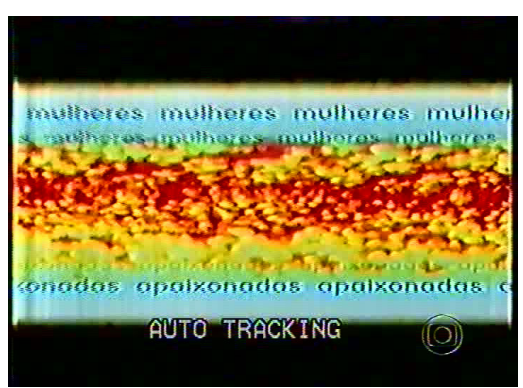

1. Início aos 4 segundos

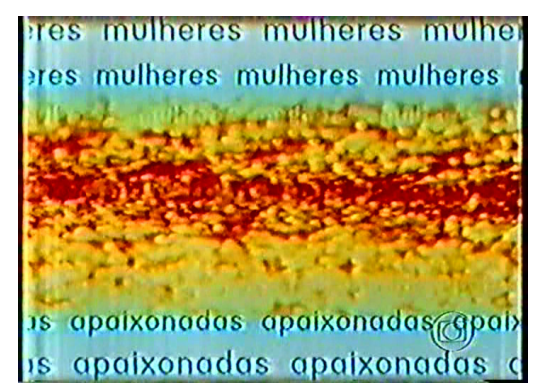

2. 5 segundos aos 6 segundos 


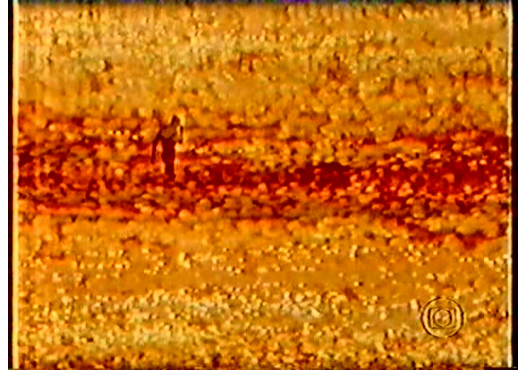

3. 7 segundos aos 15 segundos

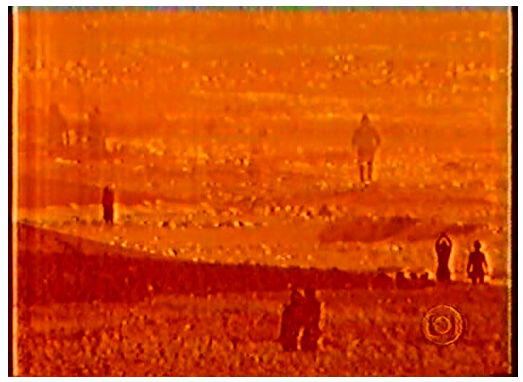

5. 18 segundos.

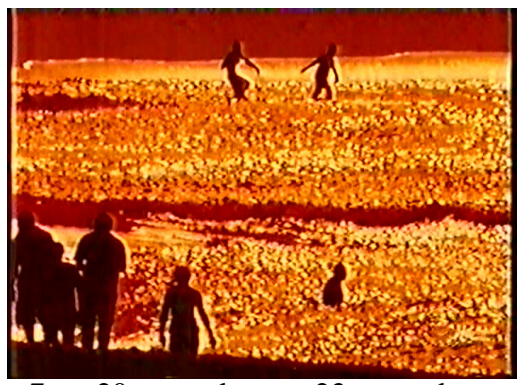

7. 20 segundos aos 23 segundos

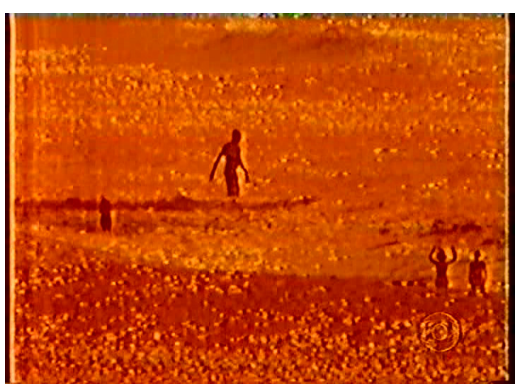

4. 16 segundos aos 17 segundos

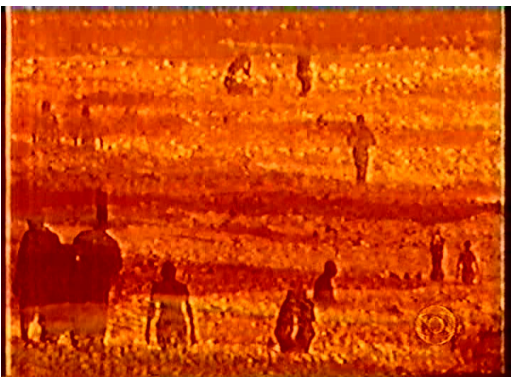

6. 19 segundos

Aos dezesseis segundos, aparece na tela a imagem 4, onde vemos o "mar" dividido por duas faixas, uma mais amarelo/ alaranjada na parte superior e outra mais avermelhada na parte inferior.

$\mathrm{Na}$ faixa laranja está o vulto de um sujeito sozinho e na faixa vermelha os sujeitos estão em dupla. Podemos, então, depreender à categoria do plano de expressão (PE), laranja vs vermelho, e podemos homologar essa categoria do PE a categoria do plano de conteúdo (PC), identidade vs alteridade. Consideramos que a identidade é o lugar do "eu" e do individual e está demarcada no texto pela cor laranja, enquanto a 
alteridade é o espaço do(s) outro(s), ou seja, do social, e está marcada no texto pela cor vermelha.

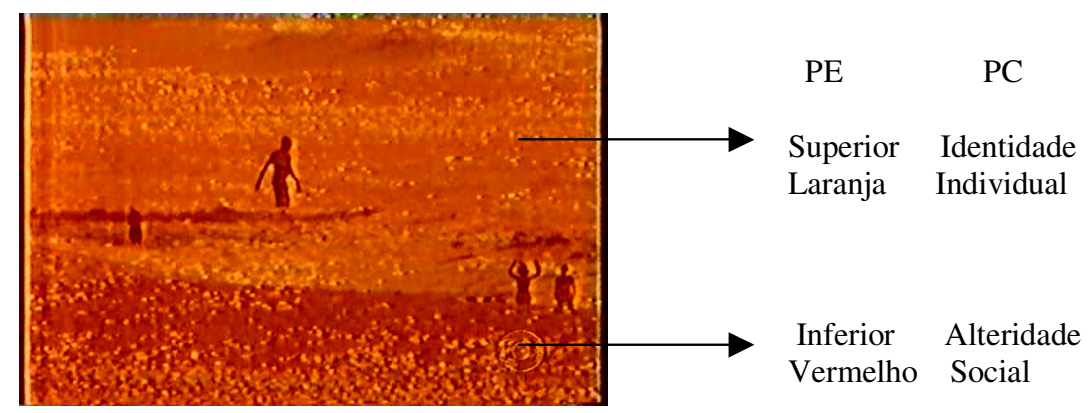

Imagem 4

As relações semi- simbólicas estabelecidas entre as categorias cromáticas do $\mathrm{PE}$ e as categorias existenciais do PC se mantêm no decorrer da filmagem, até que, na imagem 5, aos dezenove segundos, aparece os vultos de mais sujeitos.

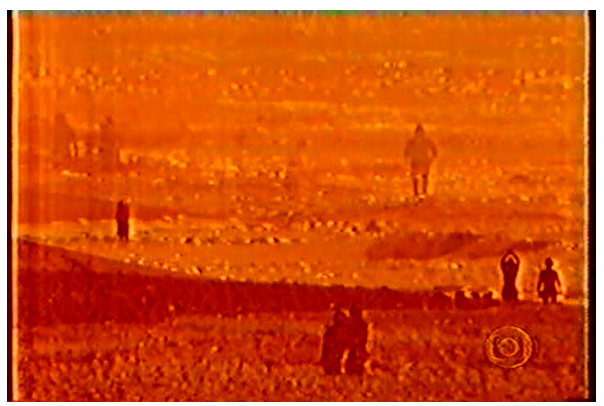

Imagem 5

$\mathrm{Na}$ imagem 6 as cores se intercalam, no entanto, as relações entre PE e PC continuam a existir e percebemos que os sujeitos A estão sozinhos e aparecem nos espaços demarcados pelo tom laranja e os sujeitos B estão próximos uns dos outros e aparecem nos espaços avermelhados. Estamos considerando a posição dos sujeitos de acordo com o apoio dos seus pés, pois salientamos que a projeção da imagem às vezes ocupa na tela os dois espaços, tanto o laranja quanto o vermelho. 


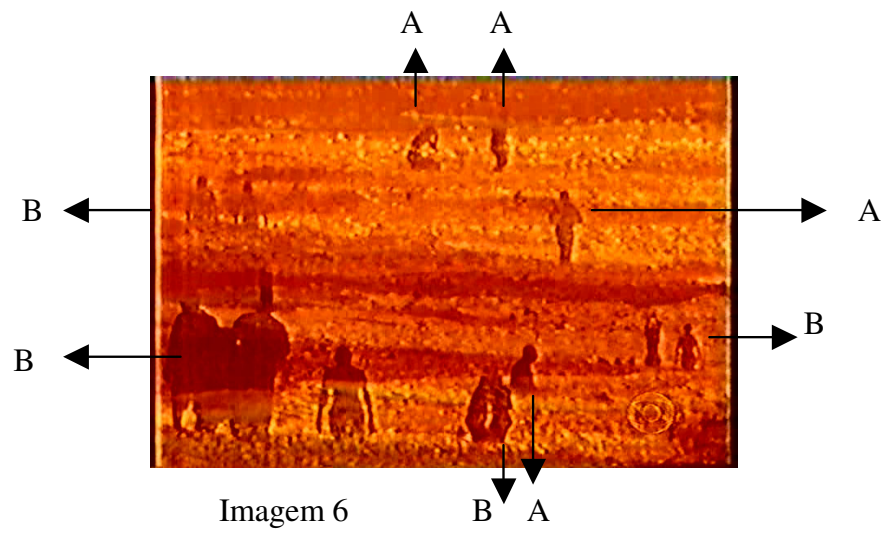

As cores, aos vinte e um segundos, voltam a se separar e constroem a imagem 7, composta por cinco faixas. Essas faixas estão distribuídas de cima para baixo, da seguinte maneira:

A primeira faixa é vermelha e apresenta uma uniformidade da cor; a segunda faixa é laranja, porém, ela apresenta uma multiformidade de tons laranjas; a terceira faixa é vermelha e divide a imagem ao meio, em superior e inferior; a quarta faixa é laranja e se compõe de várias tonalidades de laranja; a quinta e última faixa é vermelha.

A imagem 7 também deixa ver o vulto de sete sujeitos, dois sujeitos estão na faixa amarela superior, faixa 2 , um sujeito está sozinho na faixa amarela inferior, faixa 4, e quatro sujeitos estão na faixa vermelha inferior, faixa 5, mais uma vez ressaltamos que levamos em consideração o apoio dos pés, caso contrário teríamos de considerar que alguns desses sujeitos se projetam no fundo laranja. Novamente, se confirma a relação do PE /laranja vs vermelho/ com o PC /individual vs coletivo/.

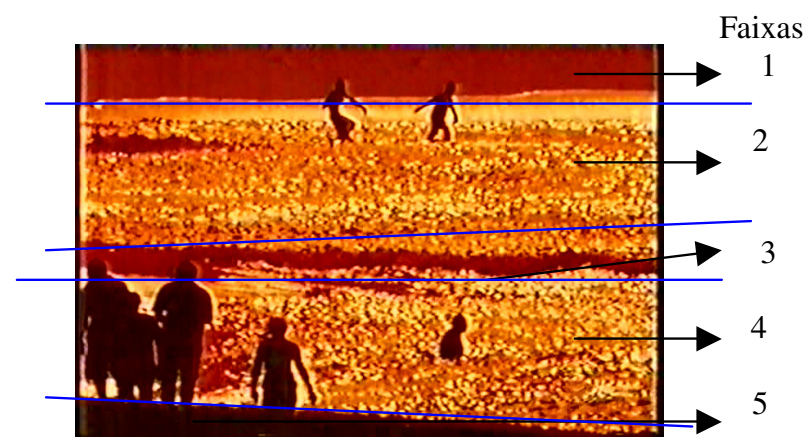

Imagem 7

Observando todas as imagens, percebemos que o jogo de cores entre laranja e vermelho estabelece um caminho de introdução para o texto da telenovela. Esse caminho é construído a partir do nome da novela, "Mulheres Apaixonadas", escrito nas 
faixas intercalantes dos primeiros seis segundos da imagem 2. O espaço superior e inferior dos intercalantes está demarcado por um fundo azul claro com as palavras escritas em letras pretas. O espaço central se demarca na faixa intercalada, pela mistura de tons das cores vermelho e amarelo, sendo que esse espaço central se alarga e constrói o caminho de introdução do texto.

Heinrich Wölfflin nos seus estudos sobre a história da arte mostra a existência de dois estilos, um estilo linear e outro pictórico, e explica:

... o estilo linear vê em linhas, o pictórico, em massas. Ver de forma linear significa, então, procurar o sentido e a beleza do objeto primeiramente no contorno - ... A visão em massa ocorre quando a atenção deixa de se concentrar nas margens, quando os contornos tornam-se mais ou menos indiferentes aos olhos enquanto caminhos a serem percorridos e os objetos, vistos como manchas, constituem o primeiro elemento da impressão. (2000: 26)

Aplicando os conceitos de Wölfflin as imagens analisadas, observamos que quando a faixa intercalada se amplia e constrói um efeito de sentido de "caminho" ou "porta de entrada" para iniciar a história as imagens estão definidas num estilo pictórico. Assim, as imagens aparecem plasticamente construídas por manchas em tons amarelos e vermelhos e apresentam uma clareza relativa.

Pietroforte, em seu livro Semiótica Visual -Percursos do olhar, relaciona os conceitos desenvolvidos por $\mathrm{H}$. Wölfflin sobre estilo linear e estilo pictórico do plano da expressão com as categorias estático vs dinâmico, do plano de conteúdo.

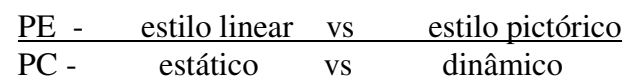

Respaldados pelos estudos de Wölfflin e as relações estabelecidas por Pietrofort entre as categorias do plano de expressão e conteúdo consideraremos as imagens dos vinte e três segundos da novela como pictóricas e logo depreenderemos a mesma relação entre as categorias dos dois planos da linguagem, PC/PE. Assim, as imagens apresentadas em forma de manchas laranjas e vermelhas deixam entrever uma clareza relativa da cena demarcando seu estilo pictórico. Ao mesmo tempo que no plano de conteúdo cria-se um efeito de sentido de dinamização dos acontecimentos, pois os sujeitos se movimentam na cena.

Voltando ao início do texto, ora analisado, percebemos que as cenas também se organizam segundo as categorias semânticas /natureza vs cultura/. A cultura está representada pelo nome "mulheres" e "apaixonadas" escrito num estilo linear nas faixas superior e inferior da tela. Enquanto, a natureza está demarcada na faixa intercalada, por uma imagem em estilo pictórico, que aos poucos deixará ver que é a água do mar. Também será nessa faixa intercalada que, logo em seguida, o vulto de pessoas aparecerão. Consideramos, em semiótica, que a natureza representa as pulsões individuais do ser humano e a cultura representa as coerções sociais. Agora, podemos, então, homologar na imagem 2 a seguinte relação semi-simbólica: 
PC

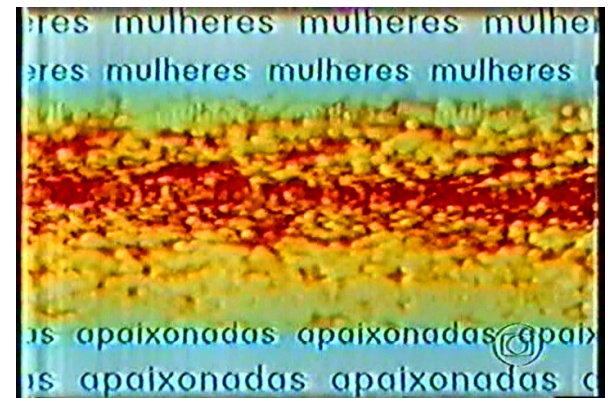

Cultura

Natureza

Cultura
PE

intercalante

Estilo

linear

intercalado

Estilo pictórico

intercalante

Estilo linear

Imagem 2

Trata-se de observar que o texto começa orientando o olhar do enunciatário para as palavras "mulheres" e "apaixonadas", essas palavras carregam em si (pré)conceitos que são sociais e que determinam papéis sociais que as mulheres ocupam. Entretanto, o texto nega a cultura, e ampliando as imagens (imagem 3) afirma a natureza. Porém, apesar de sair do domínio da cultura a imagem que estamos analisando apresenta o vulto de um sujeito e assim conserva um elemento pontual que é da cultura.

Após estabelecer as categorias do plano de expressão, intercalado vs intercalante, percebemos também que as faixas intercalantes são formadas num estilo linear, as letras estão desenhadas em linhas e seus contornos são bem definidos. Existe uma clareza absoluta das palavras. Como dito anteriormente, a faixa intercalada se forma num estilo pictórico, e não é possível definir com clareza, nesse momento, a figura da imagem.

Depois de manter durante seis segundos a relação cultura vs natureza, nega-se a cultura e predomina a natureza, pois as relações passam a ser desenvolvidas no eixo da natureza e do intercalado, na imagem 3.

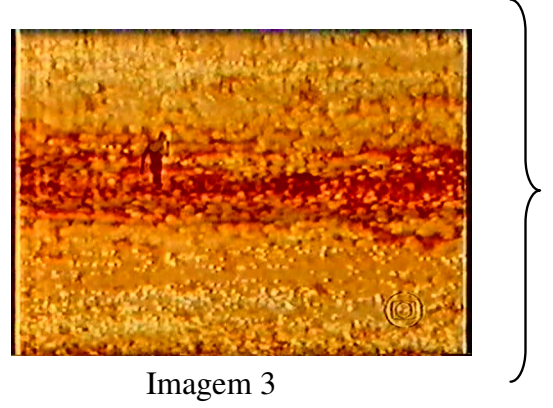

Intercalado

natureza

A ampliação do espaço intercalado, da figura 2, criou um efeito de sentido de caminho introdutório para o texto. Nesse caminho está, primeiramente, o vulto de um sujeito sozinho (imagem 3), logo em seguida aparece o vulto de mais quatro sujeitos, 
(na imagem 4), que estão caminhando dentro da água do mar. Ou seja, o que num primeiro momento era uma figura indefinida, agora, cria o efeito de sentido de água e, nessa água os homens surgem. Dessa forma, há primeiro uma afirmação da natureza apesar da presença de um sujeito sozinho, após alguns segundos a natureza é negada, porque começam a surgir outros sujeitos que representam a coletividade e, portanto, a cultura.

Aos vinte segundos, na imagem sete, tanto a cultura e o social, quanto a natureza e o individual são afirmados, uma vez que, nesse momento, os sujeitos se apresentam tanto sozinhos como em grupos. É interessante observar que nesta imagem existe uma divisão topológica do desenho em camadas, demarcada cromaticamente pelas cores laranja e vermelha. Então, percebemos que os sujeitos apresentam-se mais distantes nas faixas laranja. A faixa laranja seria aqui a água. Enquanto que os sujeitos agrupados na faixa vermelha estão mais próximos um dos outros e parecem estar na terra, ou na areia da praia. Temos, portanto, a seguinte relação semi-simbólica:

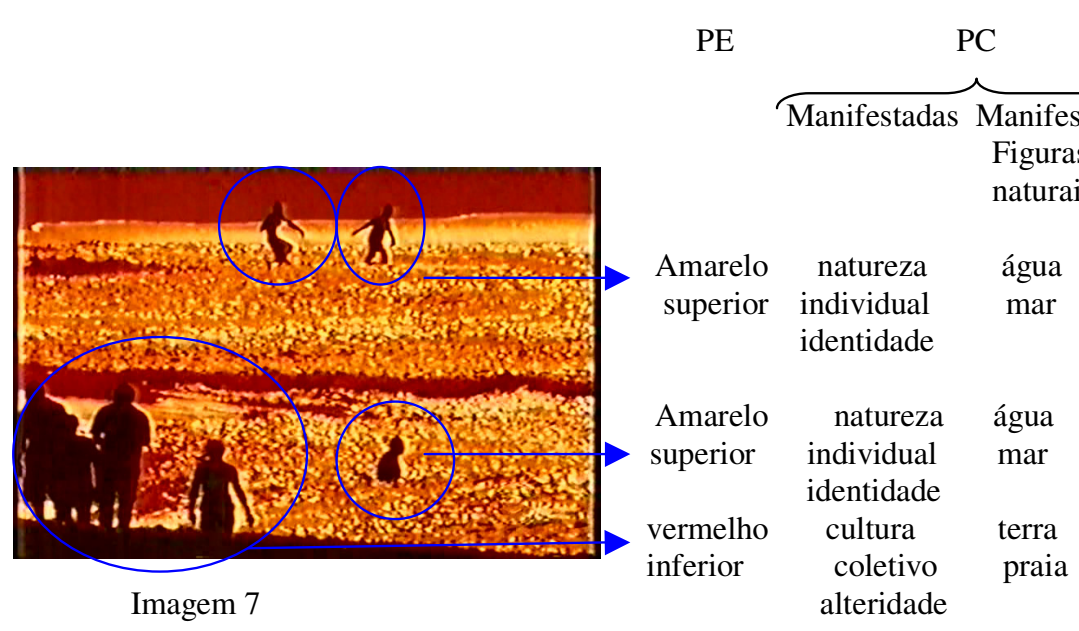

Nossa análise objetivou verificar como se organizou semi-simbolicamente a introdução do texto de "Mulheres Apaixonadas", que permaneceu no ar por mais ou menos oito meses. Percebemos a construção de um caminho dado visualmente e esse caminho apoiou-se nas categorias semânticas do plano de conteúdo /cultura vs natureza/, que podem ser aplicadas no quadrado semiótico da seguinte forma:

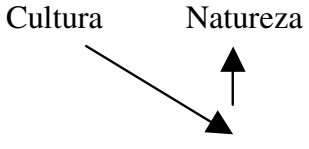

Não-cultura

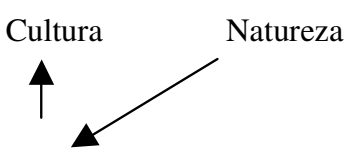

Não-natureza 
Essa seqüência, primeiramente, realizou o percurso da cultura para a natureza, nas imagens 1, 2 e 3, depois realizou o percurso inverso, da natureza para a cultura, nas imagens 3, 4, 5, 6 e 7. Portanto, o texto criou um efeito de sentido transitório, que marca a transição constante dos sujeitos entre os dois pólos do eixo /natureza vs cultura/. Ou seja, o texto instaurou, desde o primeiro momento, o simulacro de que o sujeito está em constante conflito entre suas pulsões individuais e suas obrigações sociais.

Trata-se de um jogo de persuasão do enunciador do texto que, ardilosamente, negou a cultura ao suprimir as imagens do nome "mulheres - apaixonadas" e iniciou o texto afirmando a natureza e a individualidade do ser. No entanto, esse enunciador sabe que o sujeito não é senhor de si, nem dono de suas vontades, pois também instaurou o percurso inverso da natureza para a cultura, para mostrar que os sujeitos vivem em sociedade.

\section{REFERÊNCIAS BIBLIOGRÁFICAS}

BARROS, Diana L. P. (2002). Teoria do discurso - fundamentos semióticos. 3 ed. São Paulo: Humanitas.

BARTHES, Roland (1984). O óbvio e o obtuso. Lisboa: Edições 70.

FLOCH, Jean-Marie (1985). Petites mythologies de l'oeilet de l'esprit.Paris:/ Amsterdã: Hadès/Benjamins.

(2001). Alguns conceitos fundamentais em semiótica geral. São Paulo: Centro de Pesquisas Sociossemióticas.

PIETROFORTE, Antônio V. (2004). Semiótica Visual. - Os percursos do Olhar. São Paulo: Contexto.

Wölfflin, Heinrich (2000). Conceitos fundamentais da história da arte. 4 ed. São Paulo: Martins Fontes.

\section{Como citar este artigo:}

ANTUNES, Elaine Aparecida Souto. O semi-simbolismo como ponto de partida para o texto da telenovela. Estudos Semióticos, Número 3, São Paulo, 2007. Disponível em <www.fflch.usp.br/dl/semiotica/es>. Acesso em "dia/mês/ano". 